\title{
DNA Synthesis Rescue
}

National Cancer Institute

\section{Source}

National Cancer Institute. DNA Synthesis Rescue. NCI Thesaurus. Code C41576.

DNA Synthesis Rescue involves resumption of DNA synthesis, polymeric linkage of deoxyribonucleotides by phosphate linkage, following arrest of DNA synthesis due to DNA damage. One rescue mechanism involves activation of proteins involved in DNA repair. 